\title{
Endoscopic stricturotomy with pulsed argon plasma and balloon dilation for refractory benign colorectal strictures: a case series
}

\author{
Saad Emhmed Ali, Avinash Bhakta, Robert-Marlo Bautista, Ahmed Sherif, Wesam Frandah \\ Department of Medicine, University of Kentucky, Lexington, KY, USA \\ Correspondence to: Saad Emhmed Ali. Department of Medicine, University of Kentucky, Lexington, KY, USA. Email: saad.ali@uky.edu.
}

\begin{abstract}
Benign strictures of the colon and rectum affect a sizable portion of patients who have an underlying inflammatory disease or who have undergone recent surgery. Etiologies include inflammatory bowel disease (IBD), post-surgical ischemia, anastomotic strictures, non-steroidal anti-inflammatory drugs (NSAIDs), and complicated diverticulitis. Refractory colorectal strictures are very difficult to manage and often require repeated and different treatment options. We report a novel technique using argon plasma coagulation (APC) with endoscopic balloon dilation (EBD) as a safe and effective treatment modality for refractory benign colorectal strictures. Four patients with symptomatic benign colorectal strictures were referred for endoscopic treatment. In all cases (two females and two males; average age 62 years), the endoscopic and radiographic assessment showed significant strictures (diameter, $4-13 \mathrm{~mm}$ ). The stricture was secondary to Crohn's disease in one patient and anastomotic strictures in the other three patients. Endoscopic stricturotomy through fulguration and tissue destruction using argon plasma at 1.5 liters/ minute, effect 2, and 40 watts was performed, followed by EBD. All patients were treated by one advanced endoscopist. The primary outcomes were the efficiency and safety of endoscopic stricturotomy with pulsed argon plasma and balloon dilation. The resolution of stricture was achieved in all patients. No complications were reported. We believe that combined APC with EBD is a safe and effective technique in the treatment of benign colonic stricture.
\end{abstract}

Keywords: Colorectal neoplasms; argon plasma coagulation (APC); Crohn's disease; dilation; case report

Received: 03 January 2020; Accepted: 16 March 2020; Published: 25 July 2022.

doi: $10.21037 / \operatorname{tgh} .2020 .03 .06$

View this article at: http://dx.doi.org/10.21037/tgh.2020.03.06

\section{Introduction}

Benign strictures of the colon and rectum affect a sizable portion of patients who have an underlying inflammatory disease or who have undergone recent surgery. Etiologies include inflammatory bowel disease (IBD), postsurgical ischemia, anastomotic strictures, non-steroidal anti-inflammatory drugs (NSAIDs), and complicated diverticulitis $(1,2)$.

Medical management of benign colorectal stricture is of limited utility given the fibrostenotic nature of the stricture, particularly in Crohn's disease patients. Surgical interventions, including resection and stricturoplasty, are more effective in treating colorectal strictures than endoscopic methods, but not without risks and do not prevent future colorectal stricture recurrence. Furthermore, endoscopic treatment methods are able to space out the need for surgery by an average of 6.5 years (1). Current endoscopic treatments include balloon dilation, stenting, stricturotomy, and combined endoscopic balloon dilation (EBD) with stricturotomy or stenting with a variable success rate from $75 \%$ to $90 \%$ and recurrence rate $6-18 \%$.

In certain cases, the stricture is very challenging to manage with the current endoscopic armamentarium. We decided to combine argon plasma coagulation (APC) and $\mathrm{EBD}$ as a novel therapeutic technique for refractory benign colorectal stricture in the following case series. We present the following case series in accordance with the CARE 
Guideline (3).

\section{Case presentation}

\section{Patient case 1}

A 56-year-old male presented to the clinic with intermittent right-sided abdominal pain for 6 months. Past medical

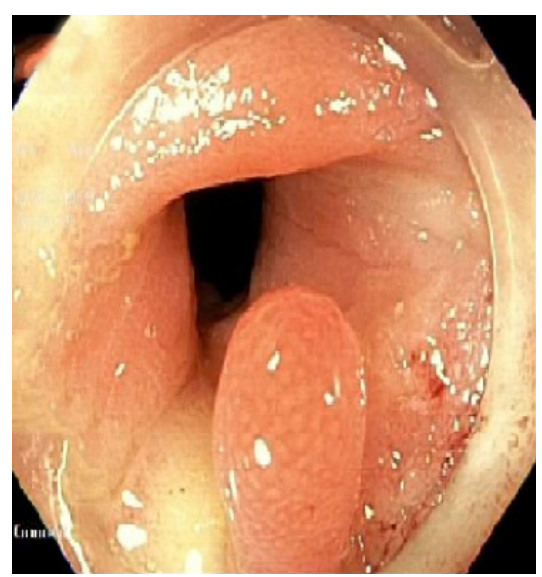

Figure 1 Colonoscopic image showing a benign-appearing, severe non-traversed stricture in the ascending colon. history was significant for the 27-year history of Crohn's disease. His maternal grandmother had colon cancer and his mother had celiac disease. He is a non-smoker and denies any alcohol or illicit drug use. He had prior use of an antiTNF inhibitor with secondary loss of response. Current medications included azathioprine and ustekinumab injection every 8 weeks. Vital signs were normal. The abdomen was soft, non-tender, no organomegaly, normal bowel sounds, and normal rectal exam. Labs revealed hemoglobin $14.2 \mathrm{~g} / \mathrm{dL}$, leukocyte count $7 \mathrm{k} / \mathrm{mm}^{3}$, platelets $393 \mathrm{k} / \mathrm{mm}^{3}$, blood urea nitrogen $13 \mathrm{mg} / \mathrm{dL}$, creatinine $1.0 \mathrm{mg} / \mathrm{dL}$, CRP $0.9 \mathrm{mg} / \mathrm{dL}$ and fecal calprotectin $59 \mu \mathrm{g} / \mathrm{g}$. Magnetic resonance enterography (MRE) revealed a severe short segment stricture of the mid ascending colon. He underwent a colonoscopy, and it showed a benignappearing, severe non-traversed stricture measuring $3 \mathrm{~cm}$ in length $\times 1.1 \mathrm{~cm}$ in inner diameter in the ascending colon that was approximately $5 \mathrm{~cm}$ distal to the cecum (Figure 1). Initially, he underwent three sessions of EBD with no improvement. The decision was made to use another modality. We started with pulsed argon plasma at flow 1.5 liters/minute, Effect 2, 40 watts for tissue ablation at the stricture edge, followed by balloon dilation up to 15 $\mathrm{mm}$, resulting in significant improvement in the luminal

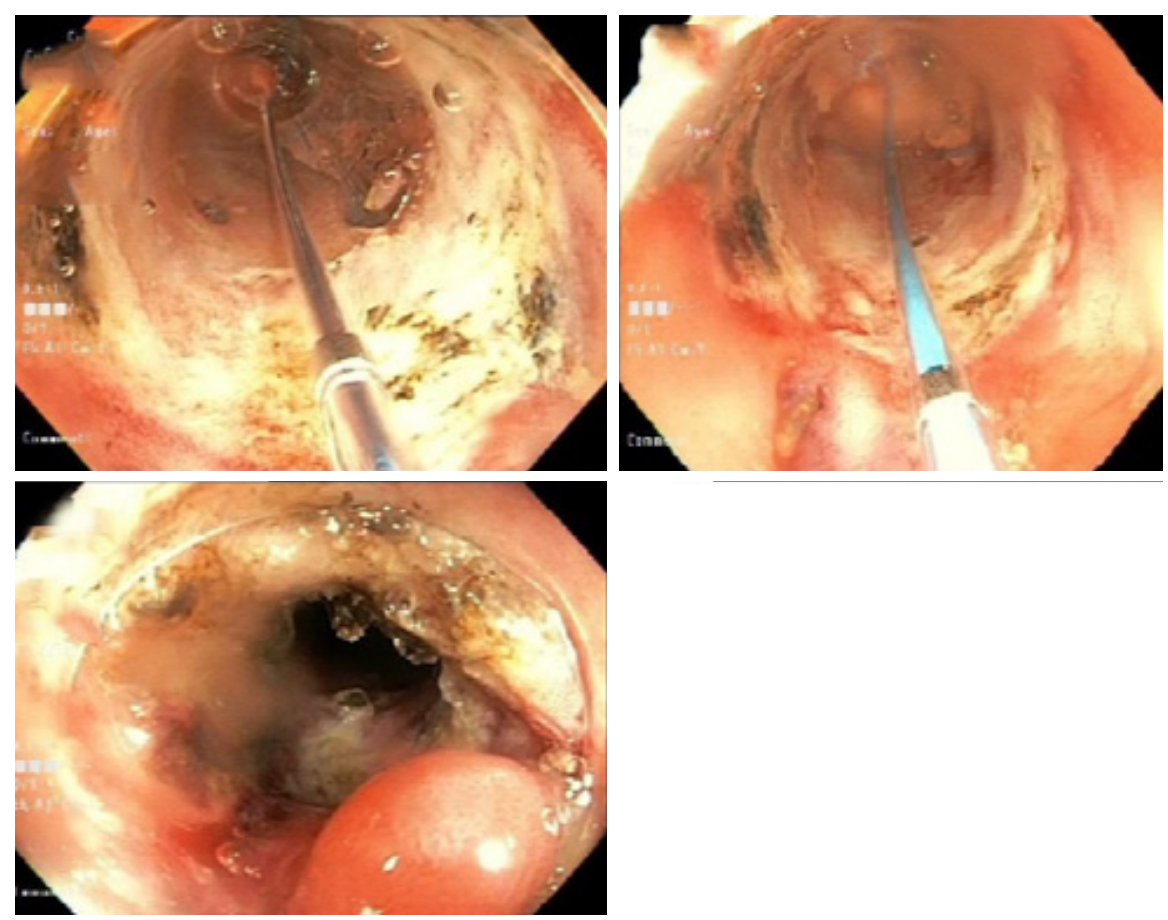

Figure 2 Colonoscopic image showing significant improvement in the stricture after pulsed argon plasma and endoscopic balloon dilation. 


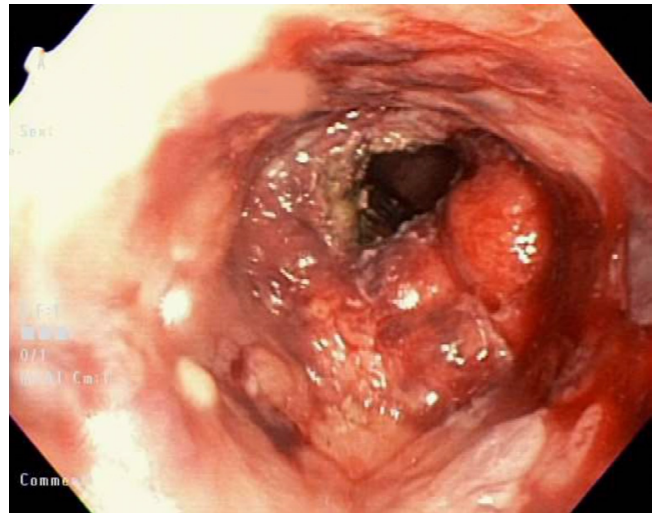

Figure 3 Colonoscopic image showing end-to-end colorectal anastomosis at $18 \mathrm{~cm}$ proximal to the anus with severe stenosis.

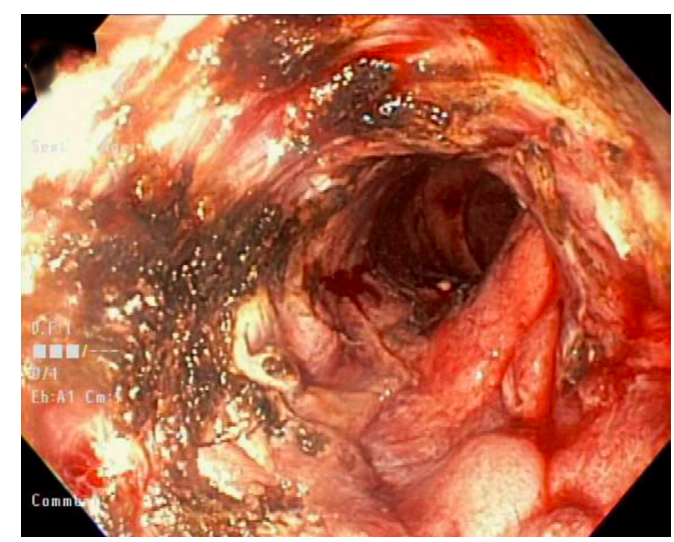

Figure 4 Colonoscopic image showing complete resolution of the anastomotic stricture after pulsed argon plasma and endoscopic balloon dilation.

narrowing (Figure 2). The stricture was successfully traversed, and the cecum was inspected. The second colonoscopy after 4 weeks showed mild stenosis, which was traversed after $15 \mathrm{~mm}$ balloon dilation. Four weeks later, colonoscopy showed improvement in the stenotic segment, and it was traversed with PCF 190 (Olympus ${ }^{\mathrm{TM}}$ ) scope with no further treatment. All the interventions mentioned above were technically successful, with no complications reported. At 3 months' follow-up, the patient was doing well, and the abdominal pain was resolved.

\section{Patient case 2}

A 70-year-old female presented to the emergency department with worsening left groin pain, and fever over the last 3 weeks. Left groin pain had been going on for 3 months with symptoms of pneumaturia and fecaluria. She had a history of breast cancer, which was treated with lumpectomy and radiation. Family history was unremarkable. She is non-smoker and denies alcohol or illicit drug use. Her temperature as 101 Fahrenheit (F). The abdomen was soft, non-tender with left inguinal hernia without induration or overlying skin changes. Labs revealed hemoglobin $10.8 \mathrm{~g} / \mathrm{dL}$, leukocyte count $24.4 \mathrm{k} / \mathrm{mm}^{3}$, platelets $686 \mathrm{k} / \mathrm{mm}^{3}$, blood urea nitrogen $18 \mathrm{mg} / \mathrm{dL}$, and creatinine $0.82 \mathrm{mg} / \mathrm{dL}$. Computed tomography (CT) of the abdomen and pelvis revealed colovesical fistula, diverticulitis, and deep abdominal wall abscess. She underwent laparoscopic low anterior resection with primary colorectal anastomosis, diverting loop ileostomy, a takedown of colovesical fistula, and drainage of the abscess. Four months later, follow-up barium enema was performed and showed severe narrowing of the distal colon and remaining upper rectum, proximal and distal to the expected position of the anastomosis. Colonoscopy revealed end-to-end colorectal anastomosis at $18 \mathrm{~cm}$ proximal to the anus with severe stenosis (5 $\mathrm{mm}$ in diameter) and was not traversed (Figure 3). She failed EBD trials using 10-12 and $12-15 \mathrm{~mm}$ diameter and fully covered stent. Pulsed APC (same settings as the first case) combined with EBD $15-18 \mathrm{~mm}$ was performed, and the stricture was traversed. One month later, repeat colonoscopy showed mild stenosis. Repeat pulsed APC with EBD up to $20 \mathrm{~mm}$ was performed with complete resolution of luminal narrowing (Figure 4). The patient tolerated the two sets of pulsed APC and EBD with no complications reported. She was doing well at 2 months follow-up, and the plan was made to reverse the diverting loop ileostomy.

\section{Patient case 3}

A 64-year-old male presented to the emergency department with a 1-day history of diffuse abdominal pain, nausea, vomiting and constipation. Six years ago, she was diagnosed with rectal adenocarcinoma and had a low anterior resection, primary anastomosis, and diverting ileostomy. $\mathrm{He}$ is a former smoker and denies alcohol or illicit drug use. Family history was unremarkable. Vital revealed a blood pressure of $95 / 63 \mathrm{mmHg}$, a pulse of 100 beats per minute, a temperature of $98.2 \mathrm{~F}$, and a respiratory rate of 12 breaths per minute. The abdomen was distended, tender to percussion, without guarding or rebound tenderness. Bowel sounds were hyperactive. Labs revealed hemoglobin 


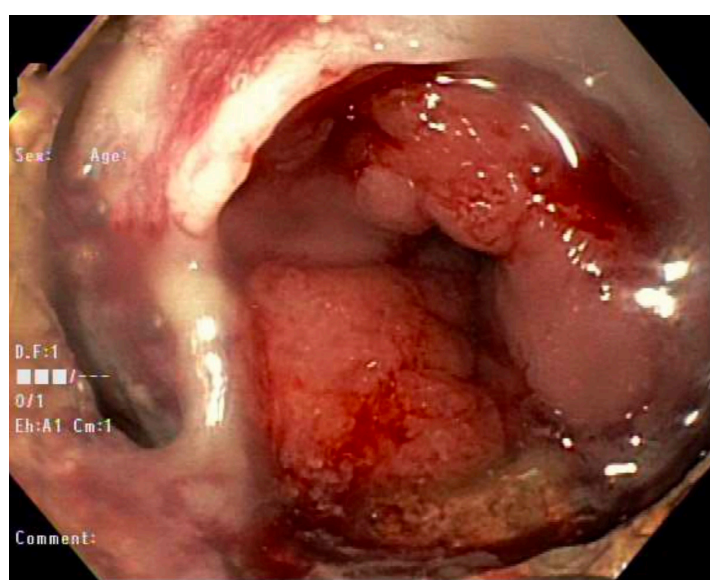

Figure 5 Sigmoidoscopic image showing a benign-appearing, severe anastomotic stricture in the rectum.

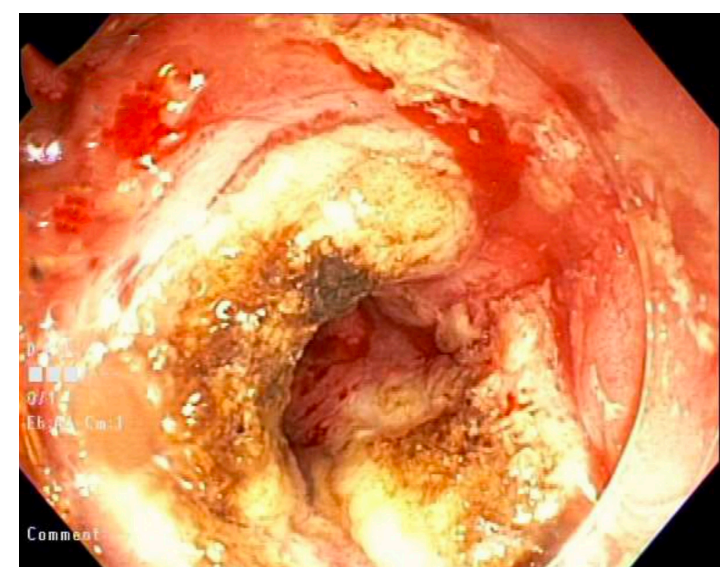

Figure 6 Sigmoidoscopic image showing significant improvement in the stricture after pulsed argon plasma and endoscopic balloon dilation.

$11.2 \mathrm{~g} / \mathrm{dL}$, leukocyte count $9.5 \mathrm{k} / \mathrm{mm}^{3}$, platelets $219 \mathrm{k} / \mathrm{mm}^{3}$, blood urea nitrogen $37 \mathrm{mg} / \mathrm{dL}$, and creatinine $1.98 \mathrm{mg} / \mathrm{dL}$. CT of the abdomen and pelvis showed diffuse dilation in both large and small bowels with air-fluid levels up to the anastomotic site in the rectum. He had a history of multiple trials of endoscopic dilation and stenting for the anastomotic stricture with the last trial was 1 month before presentation with no significant improvement in the luminal narrowing. After the patient's stabilization, flexible sigmoidoscopy was done and shown severe anastomotic stenosis in the rectum, which was $3 \mathrm{~cm}$ in length and $15 \mathrm{~cm}$ proximal to the anus (Figure 5). The stricture was biopsied and proven to be benign. It was traversed only with a diagnostic gastroscope
(GIF-190 scope Olympus ${ }^{\mathrm{TM}}$ ) with mild resistance. Pulsed argon plasma at 1.5 liters/minute and 40 watts, Effect 2 (Figure 6), followed by EBD 12-15 mm, was used. The stenosis improved and was traversed using the PCF 190 colonoscope. The patient tolerated the procedure with no complications reported. The patient's symptoms improved with the resolution of his bowel obstruction. Three months later, he was seen in the clinic and he was doing good with no acute complaints.

\section{Patient case 4}

A 58-year-old female was found to have a sizeable villous tumor of the cecum during screening colonoscopy. Past medical history was remarkable for essential hypertension, hyperlipidemia and obesity. Her paternal grandfather had pancreatic cancer, and her mother had osteoarthritis. She is a former smoker and drinks alcohol occasionally. Vital signs were normal. The abdomen was soft, non-tender, no organomegaly, normal bowel sounds, and normal rectal exam. Labs revealed hemoglobin $12.4 \mathrm{~g} / \mathrm{dL}$, leukocyte count $9.7 \mathrm{k} / \mathrm{mm}^{3}$, platelets $236 \mathrm{k} / \mathrm{mm}^{3}$, blood urea nitrogen $8 \mathrm{mg} / \mathrm{dL}$, and creatinine $1.0 \mathrm{mg} / \mathrm{dL}$. She underwent laparoscopic right hemicolectomy with ileal to transverse colon anastomosis. During surveillance colonoscopy 10 years later, she was found to be having patent side-to-side ileocolonic anastomosis, healthy-appearing mucosa of the terminal ileum, and non-patent surgical ileocolonic pouch, characterized by edema and $9 \mathrm{~mm}$ in diameter fibrotic stricture (Figure 7). To examine the pouch, we decided to start with EBD, but it was unsuccessful. Therefore, we used pulsed argon plasma at 1.5 liters/minute, effect 2 , and 40 watts with endoscopic dilation up to $12 \mathrm{~mm}$ (Figure 8). The pouch was examined and found to be healthy. The patient tolerated the pulsed APC with EBD with no technical difficulties or complications reported. Follow-up endoscopy 3 months later showed no residual stricture, and the pouch was entered without difficulty.

\section{Discussion}

Benign colorectal strictures can cause significant morbidity. They occur as a final result of inflammation cascade with resultant fibrosis. They can also be complications of several disease processes, including IBD $(1,2)$. Moreover, their occurrence can also be seen as a result of anastomotic strictures from colorectal surgery, which occurs up to $20 \%$ of all surgeries (4). 
Since 1984, the endoscopic dilation technique has become the treatment of choice for benign colorectal strictures, particularly when the stricture is secondary to post-surgical stenosis and IBD (5). Several techniques have been illustrated using dilation balloons such as wire-guided, achalasia balloon, and through the scope balloon dilation. In most cases, the technique requires multiple sessions with a gradual increase in balloon diameter until resolution of the stricture. It is an effective and safe technique with an early success rate in post-surgical stricture that reaches $100 \%$. Still, the recurrence rate of post-surgical stricture post after dilation is high and reaches up to $25 \%$ depending on stricture length (6).

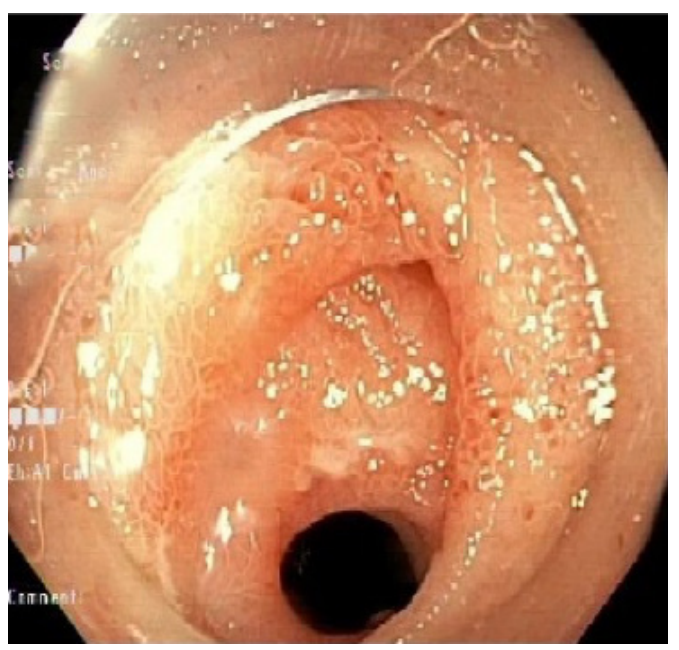

Figure 7 Colonoscopic image showing non-patent surgical ileocolonic pouch with edema and significant fibrotic stricture.
The other treatment option in the management of colorectal stricture is the use of a self-expandable metal stent. In 2015, Park et al. assessed the use of SEMS vs. dilation among 43 patients and realized no noticeable difference in resolution of stricture between two treatment modalities (5). Lately, stents made from biodegradable materials called biodegradable stents have been used in the treatment of benign post-surgical strictures. These stents need rigid guide wires for deployment, and it is useful only for distal colon stricture with least $9.4 \mathrm{~mm}$ caliber because the width of the release system is $28 \mathrm{~F}$, and length is $75 \mathrm{~cm}$ (7). The main disadvantage is early stent migration (7). There is no substantial evidence about the use of biodegradable stents in the management of benign colonic stricture.

Another treatment called endoscopic electrocautery incision (EEI) has been used for the treatment of benign anastomotic colorectal strictures. Different techniques have been described using an IT knife, hook knife, scissortype knife, sphincterotomes, or polypectomy snares. One technique is to combine EEI with argon plasma to clean the tissue between the radial incisions (8). It has been suggested that EEI is a safe and effective treatment option for short refractory benign strictures $(9,10)$. Bleeding is the primary concern using this therapy, especially intraprocedural. Recently, Lumen-apposing metal stents have been used in the treatment of benign post-surgical anastomotic stricture with promising results and low migration rates (11). However, the efficacy of these stents varies by the location of the stricture.

In our study, we used a novel combined technique of argon plasma and EBD among four patients with benign colonic strictures (three post-surgical and one due to Crohn's disease). The technical success defined as a
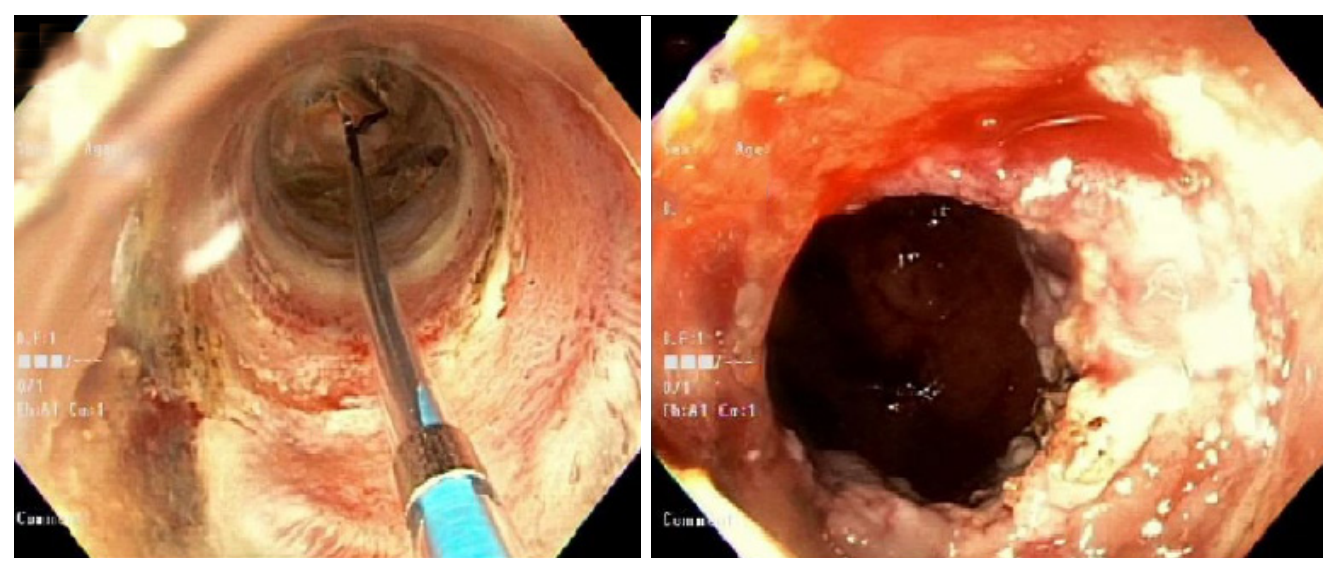

Figure 8 Colonoscopic image showing significant improvement in the stricture after pulsed argon plasma and endoscopic balloon dilation. 
Table 1 Characteristics of patients with benign colonic stricture

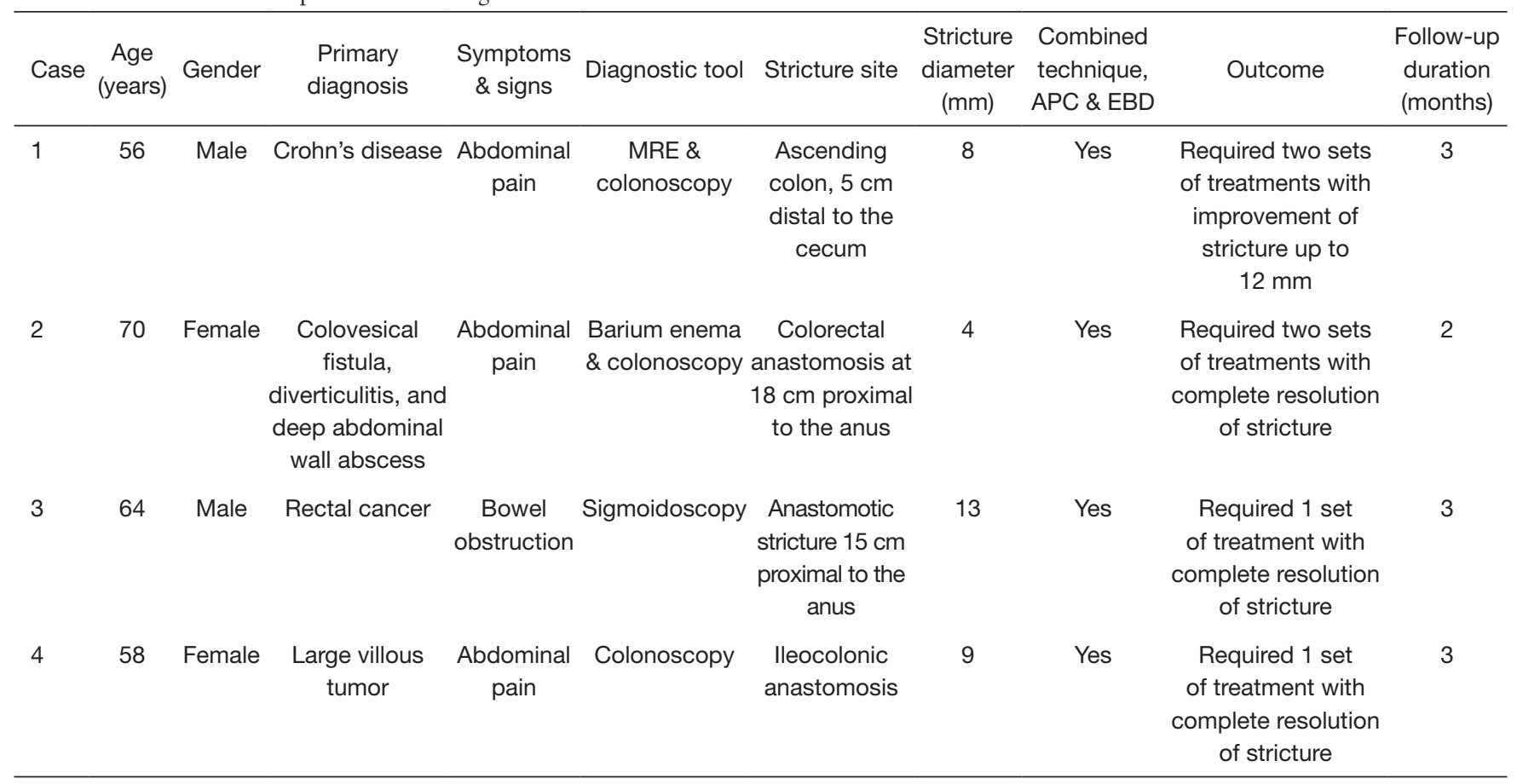

MRE, magnetic resonance enterography; APC, argon plasma coagulation; EBD, endoscopic balloon dilation.

satisfactory application of endoscopic dilation and argon plasma with no difficulty, and early clinical success defined as resolution of the symptoms or being able to traverse the stenotic stricture to examine the proximal colon) were $100 \%$. No complications were reported from this approach (Table 1).

Traditionally, APC was invented as a remote coagulation technique for the management of superficial bleeding, neoplasms of gastrointestinal, and respiratory tracts (12-15). The unique character of this technique is the ability to deliver high-frequency electrical current via the ionized argon gas without touching the ablation site. Argon is chemically inert with a bright, shining color that can be pointed under visual guidance. The ionized argon plasma has a constant depth of penetration, which is $2 \mathrm{~mm}$.

We adopted this technique from post gastric sleeve leak endoscopic therapy (16). The first step is a careful examination of the stricture and adequate position of the scope to place the stricture at the center. Then, we use the APC probe (APC; ERBE USA Incorporated, Marietta, Georgia, USA) after it was connected to ERBE generator VIO 300D. The settings are pulsed APC at flow 1.5 liters/minute, Effect 2, 40 watts. The tissue dissection starts via using the pulsed APC at one side of the stricture with close contact and slowly advance through the stricture in a perpendicular fashion, followed by EBD using $12-15 \mathrm{~mm}$ and gradually increase the size up to $20 \mathrm{~mm} . \mathrm{CO}_{2}$ is essential for these cases, and no fluoroscopy required. APC is useful in desiccation of the stricture, thus promoting hemostasis and preventing perforation. To our knowledge, combining APC with EBD technique has not been reported in the literature. We believe that combined APC with $\mathrm{EBD}$ is a safe and effective technique in the treatment of benign colonic stricture.

The limitations of our study are retrospective design with it is inheritance, a small sample size of only four patients, and short follow-up (3 months) duration that didn't allow us to identify long-term functional outcomes.

In conclusion, there are no established guidelines on how to approach patients with benign colorectal strictures. EBDs have been suggested as the first therapeutic modality. The combined technique using APC with EBD is safe and effective in treating patients with benign colorectal strictures. The procedure is reproducible and can be performed in an outpatient setting. Larger studies with longer follow-up periods are needed to validate further the long-term effectiveness and safety of this novel therapeutic technique and to compare it with other standard therapies. 


\section{Acknowledgments}

This study was submitted to the DDW 2020, Chicago, IL, USA.

Funding: Robert-Marlo Bautista, MD, is supported by an NIH/NCI Surgeon-Scientist training grant (T32CA160003). The content is solely the responsibility of the authors and does not necessarily represent the official views of the NIH.

\section{Footnote}

Conflicts of Interest: All authors have completed the ICMJE uniform disclosure form (available at https://tgh.amegroups. com/article/view/10.21037/tgh.2020.03.06/coif). The authors have no conflicts of interest to declare.

Ethical Statement: The authors are accountable for all aspects of the work in ensuring that questions related to the accuracy or integrity of any part of the work are appropriately investigated and resolved. All procedures performed in this study were in accordance with the ethical standards of the institutional and/or national research committee(s) and with the Helsinki Declaration (as revised in 2013). Written informed consent was obtained from the patients for publication of this case report and accompanying images. A copy of the written consent is available for review by the editorial office of this journal.

Open Access Statement: This is an Open Access article distributed in accordance with the Creative Commons Attribution-NonCommercial-NoDerivs 4.0 International License (CC BY-NC-ND 4.0), which permits the noncommercial replication and distribution of the article with the strict proviso that no changes or edits are made and the original work is properly cited (including links to both the formal publication through the relevant DOI and the license). See: https://creativecommons.org/licenses/by-nc-nd/4.0/.

\section{References}

1. Shen B. Interventional IBD: The Role of Endoscopist in the Multidisciplinary Team Management of IBD. Inflamm Bowel Dis 2018;24:298-309.

2. Luck A, Chapuis P, Sinclair G, et al. Endoscopic laser stricturotomy and balloon dilatation for benign colorectal strictures. ANZ J Surg 2001;71:594-7.

3. Riley DS, Barber MS, Kienle GS, et al. CARE 2013 Explanations and Elaborations: Reporting Guidelines for Case Reports. J Clin Epidemiol 2017;89:218-35.
4. Luchtefeld MA, Milsom JW, Senagore A, et al. Colorectal anastomotic stenosis. Result of a survey of ASCRS membership. Dis Colon Rectum 1989;32:733-6.

5. Park CH, Yoon JY, Park SJ, et al. Clinical efficacy of endoscopic treatment for benign colorectal stricture: Balloon dilatation vs stenting. Gut Liver 2015;9:73-9.

6. Lemberg B, Vargo JJ. Balloon dilation of colonic strictures. Am J Gastroenterol 2007;102:2123-5.

7. Jain D, Mahmood E, Singhal S. Biodegradable stents: An evolution in management of benign intestinal strictures. J Clin Gastroenterol 2017;51:295-9.

8. Schubert D, Kuhn R, Lippert H, et al. Endoscopic treatment of benign gastrointestinal anastomotic strictures using argon plasma coagulation in combination with diathermy. Surg Endosc 2003;17:1579-82.

9. Jain D, Sandhu N, Singhal S. Endoscopic electrocautery incision therapy for benign lower gastrointestinal tract anastomotic strictures. Ann Gastroenterol 2017;30:473-85.

10. Ridtitid W, Siripun A, Rerknimitr R. Stricture at colorectal anastomosis: To dilate or to incise. Endosc Int Open 2018;6:E340-1.

11. Santos-Fernandez J, Paiji C, Shakhatreh M, et al. Lumenapposing metal stents for benign gastrointestinal tract strictures: An international multicenter experience. World J Gastrointest Endosc 2017;9:571-8.

12. Grund KE, Zindel C, Farin G. Argon plasma coagulation through a flexible endoscope: evaluation of a new therapeutic method after 1,606 uses. Dtsch Med Wochenschr 1997;122:432-8.

13. Reichle G, Freitag L, Kullmann HJ, et al. Argon plasma coagulation in bronchology: a new method: alternative or complementary? Pneumologie 2000;54:508-16.

14. Sato M, Terada Y, Nakagawa T, et al. Successful use of argon plasma coagulation and tranilast to treat granulation tissue obstructing the airway after tracheal anastomoses. Chest 2000;118:1829-31.

15. van Laethem JL. Endoscopic palliation of inoperable cancer of the esophagus by argon electrocoagulation. Gastrointest Endosc 1999;50:295-7.

16. Mahadev S, Kumbhari V, Campos J, et al. Endoscopic septotomy: an effective approach for internal drainage of sleeve gastrectomy-associated collections. Endoscopy 2017;49:504-8.

doi: $10.21037 / \operatorname{tgh} .2020 .03 .06$

Cite this article as: Emhmed Ali S, Bhakta A, Bautista RM, Sherif A, Frandah W. Endoscopic stricturotomy with pulsed argon plasma and balloon dilation for refractory benign colorectal strictures: a case series. Transl Gastroenterol Hepatol 2022;7:32. 